\title{
APORTES METODOLÓGICOS PARA LA INTEGRACIÓN DEL MERCOSUR
}

\author{
CONTRIBUICÕES METODOLÓGICAS \\ PARA A INTEGGAÇÃO DO MERCOSUL
}

Miguel Ángel Ciuro Caldani

Resumen: Se utiliza el integrativismo tridimensionalista de la teoría trialista del mundo jurídico, que construye el Derecho incluyendo repartos, normas y referencias a la justicia, para presentar una metodología de la estrategia del Mercosur.

Resumo: É utilizada a integração tridimensionalista da teoria trialista do mundo jurídico que constrói o Direito, incluindo distribuições, normas e referências à justiça, para apresentar uma metodologia da estratégia do Mercosul.

Palabras clave: Integrativismo, Tridimensionalismo, Teoría trialista, Mundo jurídico, Repartos, Normas, Justicia, Metodología, Estrategia, Mercosur

Palavras-chave: Integração, Tridimensionalismo, Teoria trialista, Mundo jurídico, Distribuições, Normas, Justiça, Metodologia, Estratégia, Mercosul

\section{Introducción: ideas básicas}

1. La integración de diversos Estados ${ }^{1}$ es uno de los caminos para superar las limitaciones de la globalización/marginación $n^{2}$ que, con numerosas tensiones entre la mundialización y las reacciones de los Estados y las regiones, se produce en nuestro tiempo. Vivimos en una nueva era de la historia, signada por enormes cambios científicos, técnicos y morales que quizás culminen en las posibilidades de la genética humana. Dichos cambios incluyen también, en despliegues relevantes, las po-

1 Se puede ampliar en CIURO CALDANI, Miguel Angel, "Filosofía y sistema del Derecho de la Integración", en "Revista del Centro de Investigaciones de Filosofía Jurídica y Filosofía Social", No 29, págs. 27/48, Cartapacio, http://www.cartapacio.edu.ar/ojs/index.php/centro/ article/viewFile/899/720, 24/11/2012.

2 La globalización incluye y excluye. 
sibilidades de relacionamiento mundial brindadas por los medios de comunicación e información y la abstracción financiera. Los moldes de los Estados suelen ser demasiado pequeños para las nuevas realidades. De cierto modo estallan y se retraen el espacio, el tiempo, la materia e incluso las personas.

La integración, que puede aportar a una universalización respetuosa de las particularidades, es una opción para contribuir a superar esas dificultades haciendo más concretos los cuatro despliegues, en nuestro caso, con especial referencia al sentido espacial. Sin embargo, para que tal superación se produzca es necesario poder manejar estratégicamente $^{3}$ las fortalezas y las debilidades respectivas y esto puede lograrse aprovechando la riqueza metodológica que brinda el planteo jurídico del integrativismo ${ }^{4}$ tridimensionalista de realidad social, normas y valores. Hay que aprovechar las fortalezas y superar las debilidades con los métodos adecuados. Los caminos del tridimensionalismo permiten referir mejor el Derecho a la meta que adoptamos, consistente en ubicarlo en la vida humana en plenitud ${ }^{5}$.

2. Entre las propuestas metodológicas que podemos denominar integrativistas tridimensionalistas se encuentra la que en su momento formuló, con valor de verdadero clásico, la escuela de la libre investigación científica de François Gény. El jurista francés se refirió a lo dado y lo construido. Lo dado se constituye con los datos real, histórico, ideal y racional. Los datos son aportados por la ciencia y lo construido se basa en la técnica.

Los datos reales son las condiciones de hecho en las que se encuentran los elaboradores (realidades físicas, biológicas, psicológicas, condiciones económicas, fuerzas políticas y sociales, etc.). Los datos históricos son los procesos que han configurado las situaciones concretas, generando sus reglamentaciones. Los datos racionales se remiten al fondo esencial del Derecho natural clásico ${ }^{6}$. Los datos ideales son las aspiraciones sociales ${ }^{7}$.

3 Es posible ampliar en CIURO CALDANI, Miguel Angel, "Estrategia Jurídica”, Rosario, UNR Editora, 2011, Centro de Investigaciones de Filosofía Jurídica y Filosofía Social, http:// www.centrodefilosofia.org.ar/index.htm , 23-11-2012.

4 Consideramos en este caso la integración de despliegues jurídicos.

5 Se puede ampliar la metodología en la bibliografía que propondremos respecto del trialismo.

6 Que a nuestro parecer debería reemplazarse por la referencia a la justicia.

7 V. GÉNY, Francisco, "Método de interpretación y fuentes en Derecho Privado Positivo", $2^{\text {a }}$. ed., Reus, Madrid, 1925 (también Granada, Comares, 2000); "Science et technique en Droit Privé Positif", Sirey; "La libertad en el derecho entre la certeza y la incertidumbre", sel. y trad. María José Bernuz Beneitez, Granada, Comares, 2007. 
En el curso siguiente, a través de una versión tridimensionalista que consideramos más evolucionada, iremos mostrando cómo lo dado y lo construido se presentan en el Mercosur.

\section{Estimamos de especial interés al integrativismo tridimensiona-} lista planteado en la teoría trialista del mundo jurídico ${ }^{8}$. Para el trialismo el mundo jurídico ha de construirse incluyendo repartos de potencia e impotencia (dimensión sociológica), captados por normas (dimensión normológica) y valorados por un complejo de valores que culmina en la justicia (dimensión dikelógica $a^{9}$ ). Desde un despliegue más dinámico, el mundo jurídico consiste en la actividad relacionada con el aprovechamiento de las oportunidades de realizar repartos de potencia e impotencia (dimensión sociológica) captada por normas (dimensión normológica) y valorada por un conjunto de valores que culmina en la justicia (dimensión dikelógica) ${ }^{10}$. Los repartos resuelven relaciones de intereses y se despliegan en ámbitos de fuerza. La potencia y la impotencia se constituyen con lo que favorece o perjudica a la vida humana ${ }^{11}$. El trialismo construye el objeto jurídico con una complejidad pura ${ }^{12}$ donde se

8 Fundado por Werner Goldschmidt.

9 La palabra "Dikelogía” fue utilizada ya por Altusio, pero con un significado algo diferente.

10 Acerca de la teoría trialista del mundo jurídico c. v. gr. GOLDSCHMIDT, Werner, "Introducción filosófica al Derecho", 6a . ed., 5a. reimp., Bs. As., Depalma, 1987; "La ciencia de la justicia. Dikelogía”, Madrid, Aguilar, 1958 (2ª. ed., Bs. As., Depalma, 1986); "Justicia y verdad", Bs. As., La Ley, 1978; CIURO CALDANI, Miguel Angel, "Derecho y política”, Bs. As., Depalma, 1976; "Estudios de Filosofía Jurídica y Filosofía Política”, Rosario, Fundación para las Investigaciones Jurídicas, 1982/4; "Estudios Jusfilosóficos", Rosario, Fundación para las Investigaciones Jurídicas, 1986; "La conjetura del funcionamiento de las normas jurídicas. Metodología Jurídica”, Rosario, Fundación para las Investigaciones Jurídicas, 2000, Cartapacio de Derecho, http://www.cartapacio.edu.ar/ojs/index.php/mundojuridico/article/view/961/795 24-7-2012; "Metodología Dikelógica", Rosario, Fundación para las Investigaciones Jurídicas, 2007, Cartapacio http://www.cartapacio.edu.ar/ojs/index.php/mundojuridico/article/view/1003/883, 24-7-2012; “Distribuciones y repartos en el mundo jurídico”, Rosario, UNR Editora, 2012, Centro de Investigaciones de Filosofía Jurídica y Filosofía Social, http://www.centrodefilosofia.org.ar/index.htm, 28-7-2012; "Bases del pensamiento jurídico", Rosario, UNR Editora, 2012. En general, v. Centro de Investigaciones de Filosofía Jurídica y Filosofía Social, http://www.centrodefilosofia.org.ar/ , 23-7-2012; Facultad de Derecho de la Unicen, Portal Cartapacio de Publicaciones Jurídicas, http://www.cartapacio.edu.ar/index. cgi?wid_seccion=2\&wid_item=3,24-7-2012.

Cada teoría se construye, estratégicamente, con una meta a lograr con métodos. La meta de la teoría "pura" es, precisamente, la purificación del objeto de la ciencia jurídica; la del tomismo es en definitiva el cumplimiento de la ley eterna a través de ley divina, la ley natural y la ley humana; la del integrativismo de la teoría trialista del mundo jurídico es, como se desarrollará, lograr que se cumpla la justicia a través de la asignación a cada individuo de la esfera de libertad necesaria para que se convierta en persona. En términos más simples, la meta trialista es realizar la personalización del ser humano. Es difícil determinar qué es el ser humano, pero resulta imprescindible referirse a él, porque es lo que al menos creemos que somos y al fin debemos ser.

11 Aunque la vida humana es muy difícil de definir nos es imprescindible referirnos a ella porque vivimos. También los médicos deben remitirse a la vida y enfrentan así cuestiones análogas a las de los juristas.

12 C. por ej. GOLDSCHMIDT, “Introducción filosófica al Derecho”, cit., págs. XVII y 
hace un aporte metodológico ${ }^{13}$ que a nuestro parecer es muy satisfactorio.

En nuestro caso, nos interesa especialmente aportar metodológicamente al proceso de integración del Mercosur ${ }^{14}$. Estimamos que el Mercosur posee particular relevancia para los intereses argentinos. Como nuestro propósito es metodológico, se trata sobre todo de mostrar la importancia de las preguntas y los planteos para las respuestas. Los datos y las soluciones propuestas sólo tienen la finalidad de mostrar cómo pueden recorrerse los senderos tridimensionales de referencia. En este caso no nos ocupan al fin las soluciones, sino cómo es posible buscarlas. No pretendemos presentar "la metodología de la integración", ni siquiera "la metodología trialista de la integración" (o específicamente la integración del Mercosur) sólo brindamos aportes metodológicos para la integración del Mercosur que nos parecen satisfactorios.

ss.; BOCCHI, Gianluca - CERUTI, Mauro (comp.), "La sfida della complessità", traducciones de Gianluca Bocchi y Maria Maddalena Rocci, 10ª ed., Milán, Feltrinelli, 1997; CIURO CALDANI, Miguel Ángel, "El trialismo, filosofía jurídica de la complejidad pura”, en "El Derecho", t. 126, págs. 884 y ss.); LAPENTA, Eduardo V. - RONCHETTI, Alfredo Fernando (coord.), "Derecho y complejidad", Tandil, Universidad Nacional del Centro de la Provincia de Buenos Aires, 2011; DABOVE, María Isolina, "El Derecho como complejidad de "saberes" diversos", 2004, Cartapacio, 2004, http://www.cartapacio.edu.ar/ojs/index.php/ctp/article/ viewFile/29/17, 15-6-2012. Asimismo, GALATI, Elvio Diego, "La Teoría Trialista del mundo jurídico y el pensamiento complejo de Edgar Morin. Coincidencias y complementariedades de dos complejidades" (tesis doctoral, Facultad de Derecho de la Universidad Nacional de Rosario, 26 de abril de 2010, Sobresaliente con recomendación de publicación).

$13 \mathrm{~V}$. lo expuesto precedentemente respecto de metas y métodos de las diferentes teorías jurídicas.

14 Es posible v. por ej. Mercosur, http://www.mercosur.int/, 19-11-2012; Mercosur. Documentos oficiales, http://www.mercosur.int/t_generic.jsp?contentid=1317\&site $=1 \&$ channel=secretaria\&seccion=3, 23-11-2012; Mercosur. Normativa, http://www.mercosur.int/t_generic.jsp? contentid $=5008 \&$ site $=1 \&$ channel $=$ secretaria\&seccion $=4,23-11-2012$; Mercosur abc, http://www.mercosurabc.com.ar/, 21-11-2012; index mundi, Listado de Países, http://www. indexmundi.com/es/, 19-11-2012, también http://www.indexmundi.com/, 19-11-2012; Somos Mercosur, http://www.somosmercosur.net/, 2-12-2012; NEGRO, Sandra (dir.), "Derecho de la Integración", Montevideo-Buenos Aires, BdeF, 2010-12; SOTO, Alfredo Mario, "Temas del Derecho de la Integración", Bs. As., Estudio, 2010; ALTERINI, Atilio Aníbal (dir.), "La Integración Regional. Una Vía Relevante para la Construcción del Contrato Social en Nuestro Tiempo", 2006; ALTERINI, Atilio A. - NICOLAU, Noemí L. (directores), "El Derecho Privado ante la internacionalidad, la integración y la globalización. Homenaje al Profesor Miguel Angel Ciuro Caldani”, Bs. As., La Ley, 2005; PIZZOLO, Calogero (h.), "Pensar el Mercosur", Mendoza, Jurídicas de Cuyo, 1998; además se puede c. v. gr. FERNANDEZ ARROYO, Diego Fernando (coord.), "Derecho Internacional Privado de los Estados del Mercosur", Bs. As., Zavalía, 2003.

Aunque algunos datos difieren según las fuentes, son suficientemente representativos a los fines del texto.

Se puede v. asimismo Viajar pelo Mercosur, Mapas, http://www.mercosur.int/msweb/portal\%20intermediario/turismo_pag/ES/mapas.html, 19-11-2012. Hoy el Mercosur ha de ser también comprendido en relación con la Unasur, http://www.unasursg.org/ , 27-11-2012.

Como lo expuesto es suficiente a los fines de mostrar la metodología, dejamos de lado a los países asociados. 
4. Utilizando la teoría de las respuestas jurídicas ${ }^{15}$ es posible enriquecer la estrategia mediante métodos de "plusmodelación"16, "minusmodelación" ${ }^{17}$ y sustitución de las mismas, en los despliegues fácticos e ideales, sean éstos normativos o valorativos. Los cambios en los problemas y las soluciones, en lo sociológico, normológico y axiológico pueden ser caminos para el éxito ${ }^{18}$.

Esas variaciones pueden hacerse en la metodología para la integración del Mercosur, por ejemplo, diversificando los alcances de los acuerdos parciales, la conveniencia de nuevas incorporaciones, etc.

\section{Desarrollo: la referencia metodológica trialista al Mer- cosur}

\section{1) El mundo jurídico en general}

\section{a) Dimensión sociológica}

5. La dimensión sociológica del mundo jurídico permite desenmascarar lo que suelen presentar las normas respondiendo a los intereses de quienes las hacen. Abarca adjudicaciones de potencia e impotencia, que son distribuciones originadas por la naturaleza, las influencias humanas difusas ${ }^{19}$ y el $\operatorname{azar}^{20}$ y centralmente repartos producidos por la conducta de seres humanos determinables. La referencia metodológica jurídico-sociológica ${ }^{21}$ ha de remitirse a distribuciones y repartos. Aunque tal vez no utilizada inicialmente con la importancia que puede tener, la inclusión de la categoría distribuciones se ha evidenciado como una de las aperturas más relevantes del pensamiento del Derecho, de particular relevancia ante la complejidad del tiempo actual. Entre los grandes interrogantes metodológicos del mundo jurídico está el de re-

15 Es posible ampliar en CIURO CALDANI, Miguel Angel, “Aportes para una teoría de las respuestas jurídicas", Rosario, Consejo de Investigaciones de la Universidad Nacional de Rosario, 1976, reed. en "Investigación y Docencia", No 37, págs. 85/140, http://www.cartapacio. edu.ar/ojs/index.php/mundojuridico/article/viewFile/959/793, 24-11-2012.

16 Ampliación de las respuestas.

17 Reducción de las respuestas.

18 Puede ser útil el método de las variaciones que modifica imaginariamente los casos para averiguar qué es lo que se considera importante.

19 Aunque es difícil diferenciar la naturaleza de las influencias humanas difusas consideramos que la referencia a las dos categorías, evidenciada por el uso constante de las categorías naturaleza y cultura, puede ser esclarecedora.

20 Nos parece que la discutida categoría azar planteada desde el trialismo originario puede ser mantenida, aunque en el presente caso no la emplearemos.

21 A veces, diferenciando la consideración del objeto jurídico en sí de su referencia al resto del mundo se la nombra con la expresión "Jurística", de modo que se habla de dimensiones jurísticas. 
solver cómo se considerarán las distribuciones y los repartos existentes y cómo se producirán otros repartos. En la dimensión sociológica se encuentran sobre todo los datos real e ideal de la propuesta de Gény.

\section{a) Las distribuciones}

6. En la referencia a las distribuciones de la naturaleza cabe atender a la geografía, con sus proyecciones hidrográficas, orográficas, fitogeográficas, zoogeográficas e ictícolas en especial; de ubicación en cuanto a mares, de situación planetaria, etc.; a las características biológicas de la población, de salud, expectativa de vida, etc. Las influencias humanas difusas abarcan, por ejemplo, la economía (con sus despliegues de producción, distribución y consumo, estructura de clases, etc.); la religión; la lengua; la ciencia; el arte; la historia, la educación; la cultura general, etc. ${ }^{22}$ Puntualizando lo expuesto, cabe señalar que las distribuciones son afines de modo destacable a los datos reales e ideales de la propuesta de Gény. En ellas se realiza el valor espontaneidad.

7. La región del Mercosur tiene una composición de países con asimetría muy notable que dificulta su integración ${ }^{23}$. De cierto modo, el ingreso de Venezuela contribuye a atenuarla. El proceso "mercosureño" 24 abarca una gran extensión geográfica continua, que incluye tierras de las dos grandes proyecciones de América del Sur, sobre todo atlánticas y en parte andinas. Corresponde a un espacio oceánico atlántico que durante varios siglos vino a ser el "Mare Nostrum", pero ahora parece estar en vías de ser sustituido por el Pacífico. En su mayor parte, se sitúa en el hasta ahora dependiente hemisferio Sur. En la actualidad están quedando en el espacio mercosureño como miembros plenos la mayoría de los países del sector atlántico sudamericano. En el comienzo del Mercosur ocupaba un lugar predominante la Cuenca del Plata, de la que incluía una parte especialmente significativa. Lo que suceda en esta Cuenca tiene siempre para la Argentina, cuyo nombre incluso se asocia al río de su desembocadura, una importancia estratégica muy especial. El movimiento integrador abarcaba también gran parte de la Cuenca del

22 Se puede ampliar en CIURO CALDANI, Miguel Angel, "Distribuciones y repartos en el mundo jurídico", Rosario, UNR, 2012.

23 Es posible ampliar en CIURO CALDANI, Miguel Angel, "Meditación de la asimetría en los procesos de integración, con especial referencia a la relación del Brasil con los otros países del Mercosur", en "Derecho de la Integración”, № 8, págs. 27 y ss.

En cuanto a las diversidades entre los países hispanoamericanos y el ámbito lusoamericano, cabe ampliar en CIURO CALDANI, Miguel Angel, "El marqués de Pombal, Portugal, Brasil y el Mercosur", en "Derecho de la Integración", № 4, págs. 113 y ss.

24 Dado que se utiliza la expresión "sureño", preferimos "mercosureño" a "mercosuriano". Ninguna de las dos palabras figura en el Diccionario de la Real Academia Española (se puede v. REAL ACADEMIA ESPAÑOLA, Diccionario de la Lengua Española, Vigésima segunda edición, http://www.rae.es/rae.html, 27-11-2012. 
Amazonas. En la actualidad sucede lo propio con la Cuenca del Orinoco. En el territorio mercosureño no existen cordones montañosos que interrumpan de manera significativa la continuidad territorial, pero ésta es hasta ahora enormemente dificultada por la selva amazónica. La diversidad climática es muy amplia.

En cuanto a la extensión de los países, cabe referir, en $\mathrm{km} 2$, que la Argentina posee 2.791.810 (sudamericanos), Brasil 8.511.965, Paraguay 406.752, Uruguay 176.215 y Venezuela, 915.445. El Mercosur tiene importantes y diferentes posibilidades y magnitudes de producción agrícola, ganadera, de hidrocarburos ${ }^{25}$ y minerales. La zona cuenta con enormes recursos de agua dulce ${ }^{26}$ y el ámbito amazónico cumple una gran función en la purificación del aire del Planeta ${ }^{27}$. En general las características geográficas son una fortaleza del Mercosur.

En cuanto a la población, en cifras estimadas a 2012 la Argentina tiene 42.192.494 habitantes (2012); Brasil 205.716.890 (2012); Paraguay 6.541.591 (2011); Uruguay 3.316.328 (2011) y Venezuela 28.047.938 (2011). Las expectativas de vida en Uruguay, Argentina y Venezuela superan o alcanzan los 70 años, las de Paraguay y Brasil son inferiores. Los países mercosureños han recibido importantes corrientes migratorias, sobre todo europeas, al punto que la Argentina se ha considerado a veces un país casi europeo. También los despliegues relativamente homogéneos de la población contribuyen a viabilizar el proceso integrador.

8. En lo que se refiere a la economía, en cuatro de los países del Mercosur imperan modelos al menos relativamente capitalistas. Uno en cambio se proclama socialista. Suele afirmarse que para la viabilidad de los países mercosureños el Estado tiene que fortalecer la calidad y efectividad de las políticas monetaria y fiscal, así como promover activamente la educación, la inversión en infraestructura e innovación y el desarrollo productivo ${ }^{28}$. En diversos grados se reclama en general una

\footnotetext{
25 Se discute si el petróleo es un mineral.

26 Se destacan los acuíferos de Alter Chão y Guaraní. Se dice que el primero es el mayor del mundo.

27 Suele señalarse que la Amazonia es uno de los grandes "pulmones" del mundo.

28 Es posible v. Perspectivas Económicas de América Latina 2012, Transformación del Estado para el Desarrollo, OCDE - CEPAL, 2011, El Estado tiene además que fortalecer la calidad y efectividad de las políticas monetaria y fiscal, así como promover activamente la educación, la inversión en infraestructura e innovación y el desarrollo productivo., http://www.eclac. org/publicaciones/xml/4/44904/2011-548_Leo2011_WEB.pdf,20-11-2012; Coordinadora de Centrales del Cono Sur, Por una justa distribución de la riqueza, http://www.ccscs.org/noticias/71-destacadas/234-por-una-justa-distribucion-de-la-riqueza , 20-11-2012. Tal vez sea útil recordar, por ejemplo, CAPUTO, Orlando L.- GALARCE V., "Aspectos de la Situación Social en los Países del Mercosur. Una Visión Crítica”, Octubre, 1997, http://www.redcelsofurtado. edu.mx/archivosPDF/caputo2.pdf , 20-11-2012.
} 
mayor intervención del Estado y una más justa distribución de la riqueza, que en algunos ámbitos está muy concentrada en sectores burgueses o de predominio de cierto modo "feudal". Argentina ha sido durante mucho tiempo casi un país de clase media. Ahora hay en general, tal vez sobre todo en la recuperación argentina y el crecimiento brasileño, cierto incremento en el desarrollo de las clases medias ${ }^{29}$. Esta composición constituye una relativa fortaleza del Mercosur.

Por intereses ajenos y propios, la estructura de comunicaciones fue en gran medida construida para la vinculación con los espacios centrales internos y del hemisferio Norte, pero a veces habiéndose tomado conciencia del problema se procura superarlo. En la Argentina existen verdaderos "embudos" comunicacionales referidos al puerto de Buenos Aires y a diversos países poderosos del resto del mundo. Especial atención merece el aprovechamiento de las posibilidades fluviales ${ }^{30}$. La Cuenca del Plata es de gran valor para los países ribereños. Merecen relevante consideración los corredores bioceánicos. La estructura comunicacional es hasta ahora, sin embargo, una debilidad del Mercosur.

Otra gran cuestión económica es la disponibilidad de fuentes de energía, asunto de gran relevancia en la viabilidad de Venezuela e incluso para Brasil y en este momento crítico para la Argentina. El petróleo y el gas originan tramas de intereses especialmente complejos ${ }^{31}$. Existen además producción y cooperación hidroeléctrica importantes, por ej. en la Cuenca del Plata ${ }^{32}$. Vale recordar la gigantesca represa brasile-

29 V. Terra, Banco Mundial destaca política argentina de mejora de ingresos y reducción de la pobreza, En Argentina y Brasil, la disminución de la desigualdad de los ingresos contribuyó sustancialmente a la expansión de la clase media", detalla el documento titulado "La movilidad económica y el crecimiento de la clase media en América Latina", que también le confiere al aumento del ingreso per cápita promedio "un rol mucho más importante" en el resto de la región., http://noticias.terra.com.ar/banco-mundial-destaca-politica-argentina-de-mejora-de-ingresos-y-reduccion-de-la-pobreza,47c03f3a609fa310VgnCLD2000000ec6eb0aRCRD. html, 20-11-2012; El Nuevo Herald, 11.20.2012, BM: Clase media en América Latina aumenta $50 \%$,

Read more here:

http://www.elnuevoherald.com/2012/11/13/1343056/bm-clase-media-en-america-latina. html\#storylink=cpy,

http://www.elnuevoherald.com/2012/11/13/1343056/bm-clase-media-en-america-latina. html, 20-11-2012

30 VENESIA, Gualberto (Ing.), "Hidrovía Paraná Paraguay", http://cdi.mecon.gov.ar/biblio/docelec/dp3360.pdf, 21-11-2012; Facetas de la relación política-territorio, LLAIRO, María Monserrat (Dra.), "Los grandes proyectos de infraestructura del Mercosur, La Hidrovía Paraguay-Paraná: realidades y controversias", http://bdigital.uncu.edu.ar/objetos_digitales/3458/llairoproyeccion6.pdf, 21-11-2012.

31 Es posible v. Portal Energético Internacional, RIOS ROCA, Álvaro, "La realidad del gas", http://www.gabinete.org.ar/Noviembre_2007/gas.htm , 21-11-2012.

32 En relación con el tema se puede c. CEFIR, Atlas de energías renovables del Mercosur, Producción de Energía del Mercosur, http://cefir.org.uy/atlas/index.php?option=com_content\&view=article\&id=4\&Itemid=7 , 21-11-2012. Consumo de Energía del Mercosur, http:// 
ña-paraguaya de Itaipú, la más grande del mundo. También que hay emprendimientos como la argentino-paraguaya represa de Yacyretá-Apipé y las obras, a menudo resistidas -sobre todo por sectores ambientalistasde las zonas del Amazonas y el Orinoco.

La producción de los países mercosureños es a veces entre sí competitiva, pero en otros casos complementaria, como sucede de maneras notorias respectivamente, en el campo de la agricultura, entre la Argentina y Brasil y en el de la energía y la alimentación entre la Argentina y Venezuela ${ }^{33}$. El proceso integrador ha incrementado el comercio intrazona, pero múltiples barreras han evitado que tuviera los alcances debidos $^{34}$. Los intereses de los países mercosureños están entramados de modo que, por ejemplo, la Argentina depende mucho de lo que suceda en Brasil e incluso en Venezuela y Uruguay depende en ciertos aspectos de lo que suceda en la Argentina. Al fin parece que lo que más importa a veces es la comercialización externa, por ejemplo con China. El gigante asiático es un factor de recomposición de la estructura económica mundial. Un aspecto del proceso que ha motivado conflictos importantes entre la Argentina y Uruguay es la tensión entre la conservación del medio ambiente y la industrialización, cuyo desenvolvimiento generó sucesos ajenos a lo que puede esperarse de un camino integrador ${ }^{35}$. Los países mayores del área evidencian importantes dificultades de integración interna que han llevado a afirmar, por ejemplo, que el Mercosur originario respondía sobre todo a los intereses de Buenos Aires y San Pablo. La producción competitiva y la atracción externa son debilidades; la complementariedad es una fortaleza.

Hoy Brasil es referido como parte del grupo de países de gran

cefir.org.uy/atlas/index.php?option $=$ com_content\&view $=$ article\&id=3\&Itemid $=6 \quad, \quad 21-11$ 2012; La energía en el Mercosur al 2025, http://www.ambiental.net/coscoroba/hontyenergia/ HontyEnergiaAmbDesarrolloCap5.pdf, 21-11-2012.

33 Mercosur abc, MASI, Fernando, "Integración Productiva: la salida competitiva para las economías pequeñas del Mercosur", http://www.mercosurabc.com.ar/nota.asp?IdNota $=3272 \& I d S e c c i o n=7.21-11-2012$

34 V. por ej. Cámara Argentina de Comercio, http://www.cac.com.ar/noticia/INFORME_ MERCOSUR_ELABORADO_POR_EL_DEPARTAMENTO_DE_ECONOMIA_DE_LA_ CAC_3248, 21-11-2012

35 Cabe recordar por ejemplo: Cour Internationale de Justice, Usines de Pâte à papier sur le fleuve Uruguay (Argentine c. Uruguay), http://www.icj-cij.org/docket/files/135/10779.pdf, 26-11-2012 ; American Society of International Law, Pulp Mills on the River Uruguay: The International Court of Justice Recognizes Environmental Impact Assessment as a Duty under International Law

By Cymie R. Payne, http://www.asil.org/insights100422.cfm, 26-11-2012). GEIC,

CIPOLATTI, Verónica, "Caso Papeleras: el Fallo de la Corte Internacional de Justicia y sus repercusiones nacionales e internacionales", http://geic.files.wordpress.com/2010/12/nota_de_ opinon_fallo_de_la_hayal.pdf, 21-11-2012. 
territorio y población constitutivo del espacio "Brics". Sus proyecciones principales no siempre están remitidas al Mercosur. Quizás a través de su amistad con Venezuela y tal vez por cuestiones energéticas la Argentina se aproxime a Irán, cuya producción respectiva puede serle de interés $^{36}$. Todo lo que se resuelva en los países del Mercosur y en el proceso en conjunto ha de tener en cuenta la crisis del capitalismo central, principalmente en la Unión Europea. En general, la economía constituye una complejidad de fortalezas y debilidades del proceso integrador.

9. La religión predominante en el Mercosur es el catolicismo, aunque también hay presencia de otras orientaciones cristianas, el judaís$\mathrm{mo}^{37}$, el Islam, la tradición umbanda, etc. ${ }^{38}$. Asimismo hay orientaciones sincréticas, sobre todo en Brasil. En los últimos tiempos, desde Brasil se ha desarrollado la Iglesia Universal del Reino de Dios, con ciertas afinidades pentecostales ${ }^{39}$. Brasil es el país con más presencias católica y espiritista en el Planeta. La herencia católica constituye la base religiosa de todos los países mercosureños, aunque hay importante espacio de quienes se llaman católicos no practicantes. Esta herencia permite considerar con especial interés la explicación weberiana de la menor aptitud de los países católicos para el desarrollo capitalista ${ }^{40}$. Algunos piensan que la expansión de ciertas orientaciones protestantes estaría ligada a la obra norteamericana para debilitar el sentido nacionalista de los países de la región. La afinidad religiosa básica constituye, de todos modos, una fortaleza mercosureña.

10. Si se ha podido decir incluso que el hombre es su lenguaje, mucho vale considerar que las lenguas mercosureñas dominantes, el español y el portugués, son derivaciones latinas muy próximas ${ }^{41}$. Incluso, sobre todo en regiones de fronteras, hay híbridos que integran las dos lenguas. El español y el portugués conviven en diversas medidas con lenguas indígenas, como la importante lengua guaraní que, junto al español, es oficial en Paraguay. La supervivencia del guaraní en Paraguay suele ser explicada por el carácter mediterráneo del país y la fuerte influencia educadora de las madres, que la transmitieron a sus hijos. Sin

36 También se ha de atender a las dificultades financieras internacionales del país rioplatense.

37 Las colectividades judías de la Argentina y Brasil figuran entre las mayores del mundo.

38 Es posible v. Asociación de Cientistas Sociales de la Religión en el Mercosur, http:// www.naya.org.ar/religion/histor.htm, 21-11-2012; Escuela de Umbanda del Mercosur, http:// escueladeumbanda.blogspot.com.ar/2010/03/ciclo-2010-promocion-exclusiva-para.html, 21-11-2012.

39 Caracterizada por promesas de curas milagrosas, prosperidad y cambios vida y a menudo apoyada en testimonios de conversos.

40 Es posible c. WEBER, Max. "La ética protestante y el espíritu del capitalismo”, trad. Luis Legaz Lacambra, 2a ed., Barcelona, Península 1973.

41 También denominadas "romances" o "románicas". 
embargo, todas las lenguas mercosureñas se encuentran bajo la presión globalizante del inglés. Por primera vez en siglos la lengua dominante en el mundo no es de origen latino sino en gran medida germánica. El despliegue lingüístico muy afín es una fortaleza muy grande para el Mercosur.

11. Los países del Mercosur tienen acervos científicos y técnicos de nivel intermedio. Todos poseen una organización estructurada en consejos nacionales de investigaciones científicas y técnicas y organismos especializados por áreas ${ }^{42}$. En cuanto a distinciones en ciencias naturales, cabe referir que la Argentina cuenta con tres premios Nobel (uno nacionalizado británico), Brasil fue lugar de nacimiento de uno y Venezuela fue sitio de nacimiento de otro que se desarrolló profesionalmente en los Estados Unidos de América ${ }^{43}$. El enfoque científico y técnico en colaboración es una vía de fortaleza para la integración mercosureña ${ }^{44}$.

12. El potencial artístico de los países del Mercosur es muy relevante. En el ámbito arquitectónico cabe destacar por ejemplo al argentino César Pelli y al brasileño Oscar Niemeyer; en el de la literatura, v. gr. al argentino de amplia dimensión universal Jorge Luis Borges, su de cierto modo connacional Julio Cortázar ${ }^{45}$, el brasileño José Mauro de Vasconcelos, el paraguayo Augusto Roa Bastos, el uruguayo Eduardo Galeano y los venezolanos Rómulo Gallegos y Arturo Uslar Pietri; en la música, al argentino Astor Piazzolla, el brasileño Heitor Villa-Lobos y el venezolano Inocente Carreño; en la danza, al argentino Jorge Don, etc. El espacio artístico es una fortaleza para la integración del Mercosur.

13. En el campo histórico cabe mencionar la ubicación de los pueblos precolombinos, diversa de las divisiones impuestas por las potencias europeas conquistadoras, como es el caso de la familia lingüística tupí-guaraní, que ocupó partes de la Argentina, Paraguay y Brasil ${ }^{46}$. Las potencias ibéricas que se asentaron en las tierras mercosureñas transpusieron su cultura sobreponiéndola a las de los pueblos indígenas. En

42 Es posible c. Slideshare, CAMPERO, Esteban, "Los sistemas nacionales de innovación en los países del Mercosur. Diferencias y similitudes y políticas de conjunto", 25 de junio de 2008, http://www.slideshare.net/estebancampero/mercosur-488194, 21-11-2012.

43 Científicos uruguayos compartieron el premio Nobel de la Paz (v. Presidencia República Oriental del Uruguay, http://archivo.presidencia.gub.uy/_web/noticias/2008/04/2008040708. htm, 21-11-2012).

44 V. por ej. Programa marco de Ciencia, Tecnología e Innovación del Mercosur para el período 2008-2012, http://www.recyt.mincyt.gov.ar/files/ProgramaMarco/programa_marco_espanol.pdf, 27-11-2012.

45 Nacido en Bélgica y nacionalizado francés.

46 Es posible ampliar en CIURO CALDANI, Miguel Angel, “Tres reflexiones filosófico históricas sobre la vida de los guaraníes", en "Boletín del Centro de Investigaciones de Filosofía Jurídica y Filosofía Social”, No 4, págs. 63 y ss. 
el ámbito del Mercosur España armó el Virreinato del Río de la Plata y la Capitanía General de Venezuela y Portugal constituyó el principado y el reino de Brasil. Múltiples conflictos se produjeron en Sudamérica entre Portugal y España y luego entre Portuga ${ }^{47}$ y Brasil y las Provincias Unidas del Río de la Plata, en cierta medida sucesoras del Virreinato. La unión virreinal fue constituida reordenando diversos territorios y con miras a frenar la influencia portuguesa en la Cuenca del Plata. Al independizarse, las tierras del Virreinato del Río de la Plata se desintegraron, en tanto Brasil conservó su unidad territorial. Esta diversidad de caminos se debió en parte considerable a la injerencia británica, que dividía a los países hispánicos para acentuar su dominio, en tanto no lo hacía con la esfera de cultura lusitana, según los casos, más o menos amiga. La existencia misma de Uruguay como Estado "de equilibrio", surgió de la intervención brasileña favorecida por Gran Bretaña. Entre 1864 y 1870 se desarrolló entre países de la Cuenca la Guerra de la Triple Alianza que, aunque el tema se discute, parece ser en parte una expresión más de la permanente intervención inglesa en la región. En ese conflicto la Argentina guerreó contra los que eran, evidentemente, sus intereses permanentes. Como resultado de la lucha, Paraguay padeció un desastre demográfico casi totalmente infundado y quedó durante largo tiempo sometido a excesivas influencias brasileñas y argentinas.

Durante muchos años la Argentina y Brasil tuvieron sus relaciones dominadas por hipótesis de conflictos hasta que en 1985 se firmó la Declaración de Foz de Iguazú que se plasmaría, con un espíritu más comercial, en el Tratado de Asunción que sirve de base al Mercosur ${ }^{48}$. Las orientaciones en cuanto a "cuestiones de Estado", de interés permanente del país, son mucho más sólidas en Brasil que en la Argentina. Los países más pequeños han tenido a veces ciertos temores ante los mayores. El relato de la historia de los países de la región fue construido con referencia a conflictos que deben ser superados.

Antes del proceso del Mercosur los países de la región participaron en intentos de integración que no fueron satisfactorios. Todos los países mercosureños son parte de la nueva Unasur ${ }^{49}$. La evolución de los últimos años ha mostrado que la confluencia de intereses asumida por los gobiernos es limitada. Incluso dentro del proceso, parece que en la actualidad hay una posibilidad de especial afinidad paraguayo-bra-

47 En cierto momento Reino Unido de Portugal, Brasil y Algarve.

48 V. MARTINEZ, María Celia y otros, "Cronología del Mercado Común del Sur (Mercosur): Principales acontecimientos en los 20 años de existencia del bloque 1991-2011”, en NEGRO, op. cit., t. II, 2012, págs. 233 y ss.

49 Paraguay fue suspendido. 
sileña ${ }^{50}$ y otra venezolano-argentina. Vale reflexionar acerca de si para los intereses permanentes de la Argentina, más allá de la circunstancia energética, esta referencia paraguaya a Brasil es resultado de un error estratégico propio. La perspectiva histórica es ámbito de fortalezas y debilidades mercosureñas.

14. En el campo educativo, según los datos disponibles los países del Mercosur presentan los siguientes índices de analfabetismo: Uruguay, 2; Argentina, 3; Paraguay 6; Venezuela, 7 y Brasil 12. Mucho es lo que puede hacerse para la integración en el campo de la educación. Se ha estructurado el Mercosur Educativo y cabe referir en particular la importancia que desde esta perspectiva tienen las instituciones universitarias $^{51}$. En general las realidades y las posibilidades educativas son fortalezas que contribuyen de manera destacada a la viabilidad del proceso integrador.

15. En el ámbito de la cultura en general cabe destacar la diversidad de los elementos anglofranceses e hispánicos tradicionales de la cultura ibérica peninsular, especialmente hispánica, reproducidos en América. España e incluso Portugal no fueron protagonistas de la Modernidad, ni de las Revoluciones Burguesas, ni de la Revolución Industrial. Tal vez por eso quedaron diferenciadas en esos dos ámbitos culturales.

El despliegue cultural anglofrancés es más abstencionista, afín a la Reforma, individualista e ilustrado. A menudo es más republicano ${ }^{52}$ y liberal. Entre sus grandes representantes están Carlos III $^{53}$ y de cierto modo Pombal ${ }^{54}$. Cabe mencionar también a Miranda, Moreno, Belgrano, Pedro II, Rivadavia, Rivera, Mitre, Sarmiento, los Alvear, Aramburu, etc. En la Argentina estuvo representado en gran medida por el partido

50 UltimaHora.com, 27 de Noviembre de 2012, Franco sostiene que Paraguay se debe "pegar" al Brasil para desarrollarse, http://www.ultimahora.com/notas/580529-Franco-sostiene-que--Paraguay--se-debe-pegar-al-Brasil-para-desarrollarse, 27-11-2012.

51 V. Aporte a la comprensión del: Mercosur Red Académica Uruguaya, La educación, http://www.rau.edu.uy/mercosur/faq/pre26.merco.htm, 22-11-2012; Ministerio de Educación, Presidencia de la Nación, DNCI, Programa de desarrollo del Sector Educativo del Mercosur, http://www.me.gov.ar/dnci/merc_index.html, 22-11-2012; Ministerio de Educación, Presidencia de la Nación, Instituto Nacional de Formación Docente, Mercosur, Programa de Apoyo al Sector Educativo del Mercosur para Formación docente (PASEM), http://portales.educacion.gov.ar/infd/mercosur/, 22-11-2012; Asociación de Universidades Grupo Montevideo, http://grupomontevideo.edu.uy/, 22-11-2012. Es posible ampliar en CIURO CALDANI, Miguel Angel, "Meditación sobre la tarea jurídica universitaria en los marcos de la integración y la globalización/marginacion (A la búsqueda de la universalización)”, en "Derecho de la Integración”, No 12, págs. 52/56.

52 En el sentido de la división de poderes.

53 Vale diferenciar a los angloafrancesados considerados en el texto de los específicamente afrancesados españoles partidarios de José I.

54 Se puede v. el artículo "El marqués de Pombal ...” cit. 
unitario, que buscaba el predominio del puerto de Buenos Aires. En Uruguay parece claro referirlo a la línea del Partido Colorado, más cercano a Brasil y por cierto tiempo a Pedro II. En el campo arquitectónico cabe remitirse, por ejemplo, al italianizante Palacio Real de Madrid y al barrio porteño de la Recoleta.

El despliegue cultural hispánico tradicional y en sentido amplio ibérico tradicional es más intervencionista, afín al catolicismo tradicional, comunitarista y romántico. Suele referirse más a Santo Tomás de Aquino y Suárez e incluso a la democracia rousseauniana, a menudo con fuerte predominio de las mayorías. Entre sus grandes representantes europeos figura Felipe II. En el ámbito rioplatense cabe mencionar a Rosas, Oribe, Perón, Duhalde, etc. ${ }^{55}$ En Uruguay resulta también claro remitirse a la línea del Partido Nacional (Blanco). En Brasil es posible mencionar a Vargas, Quadros, Goulart, Brizola, etc. También el venezolano Chávez puede ser ubicado en este ámbito. En el campo arquitectónico vale atender como expresiones hispánicas tradicionales al Monasterio de El Escorial y el barrio porteño de San Telmo o la ciudad de Salta ${ }^{56}$. Gran parte de las guerras civiles que se produjeron en la región estuvo motivada por conflictos entre anglofranceses e hispánicos tradiciona$\operatorname{les}^{57}$.

Otros temas relevantes desde el punto de vista de la cultura son los de las migraciones y la multiculturalidad. Si bien suele haber asimilación, en países como la Argentina se presenta a veces cierto rechazo a migraciones de origen no europeo ${ }^{58}$.

\section{Creemos que puede sostenerse que el sector hispánico tradicional}

55 Aunque las relaciones entre ambos no fueron buenas, cabe mencionar que Oribe, a semejanza de lo que había sido Artigas, puede ser considerado un héroe de las luchas argentinas. Rosas y Oribe fueron "demonizados" por la historia oficial escrita por los anglofranceses y tuvieron que ser reivindicados largo tiempo después de su muerte.

Aunque tiene ciertas afinidades anglofrancesas "progresistas" el gobierno argentino actual, a semejanza del chavismo, posee relaciones importantes con el estilo hispánico tradicional. Esgrime un fuerte planteo opuesto a intereses británicos.

56 Es posible ampliar en CIURO CALDANI, Miguel Angel, "Bases Jusfilosóficas del Derecho de la Cultura", Rosario, Fundación para las Investigaciones Jurídicas, 1993; "Estudios Jurídicos del Bicentenario", Rosario, UNR Editora, 2010, Centro de Investigaciones de Filosofía Jurídica y Filosofía Social, http://www.centrodefilosofia.org.ar/index.htm, 2311-2012; "Aportes jusfilosóficos para la comprensión de las condiciones constitucionales de los Estados hispanoamericanos y de su aptitud para la integración", en "Anuario de Derecho Constitucional Latinoamericano", 13 × año, t. II, págs. 725/739.

57 Como en parte se ha referido en el texto y salvando diferencias no del todo irrelevantes, en la Segunda Guerra Mundial cabe referir el sector anglofrancés a las potencias "atlánticas" y el espacio ibérico tradicional a las del Eje europeo, sobre todo a Italia.

58 Unesco, CALDERON G., Fernando - SZMUKLER, Alicia B., "Aspectos culturales de las migraciones en el Mercosur", referido principalmente al caso de los inmigrantes bolivianos, http://www.unesco.org/most/calderon.htm, 23-11-2012. 
tiene más inclinación a la integración con los propios países hispánicos, pero en general la escisión entre anglofranceses e hispánicos tradicionales, con las tensiones que produce, puede ser considerada también una debilidad del proceso mercosureño.

\section{b) Los repartos}

16. Los repartos se producen, también en despliegues de fuerza, en espacios de distribuciones y de otros repartos. Hay que aprovechar las oportunidades respectivas. Se han de reconocer realidades en las que se toman y ejecutan decisiones mediante lo que se considera el ejercicio de la libertad. Para que haya conducta tiene que haber libertad, y debe producirse un ejercicio lúcido de ella. El ejercicio de la libertad se hace más lúcido cuando se cuenta con la metodología de las perspectivas socio-normo-dikelógicas del trialismo. En los repartos se satisface el valor conducción.

Para considerar los repartos hay que atender a los repartidores (conductores), los recipiendarios (beneficiados y gravados), los objetos (potencias e impotencias), las formas (caminos para iniciarlos) y las razones (móviles, razones alegadas y razones que en su caso atribuye la sociedad cuando considera que son valiosos). Por ejemplo: es relevante establecer cuáles son y serán las formas -procesales o de mera imposición, negociales o de mera adhesión- como caminos previos de mayor o menor audiencia para la toma de decisiones. El campo de los alegatos suele ser muy diverso de lo que se quiere. La fuerza de desenmascaramiento de la noción de reparto tiene destacada significación.

Es en marco complejo de distribuciones y repartos, con fortalezas y debilidades, que ha de producirse la conducción repartidora mercosureña. Es necesario contar con la fuerza necesaria para cambiar la realidad y con la libertad y la lucidez debidas para producir las conducciones pertinentes. A veces los repartidores mercosureños son y serán otros que los expresados en las normas y mucho de lo que se decide y decidirá al respecto depende del gran poder que no sólo en las normas sino en los hechos ejercen y ejercerán los respectivos Presidentes. Asimismo vale atender todavía a cierto predominio de sectores económicos regionales y extrarregionales y a la insuficiencia de la participación democrática $^{59}$. Cabe recordar que, como ha sucedido hasta no hace mucho en países de nuestro continente, algunas medidas económicas pueden

59 Se puede ampliar en CIURO CALDANI, Miguel Angel, "Significados de los órganos de gobierno del Mercosur", en "La Ley - Voces Jurídicas Gran Cuyo", Año 3, Número 4, 1998, págs.279/285; CORREA FREITAS, Ruben, "Los órganos del Mercosur: hacia la conformación de un Parlamento común", UNAM, http://www.juridicas.unam.mx/publica/librev/rev/ dconstla/cont/2005.2/pr/pr21.pdf, 2-12-2012. 
producir sumisión a la injerencia de gobernantes de organismos financieros internacionales. Importa atender a qué repartidores judiciales, arbitrales, financieros, etc. intervendrán en la solución de los conflictos de particulares y de gobiernos.

Es muy relevante considerar quiénes se benefician y se beneficiarán, se perjudican y perjudicarán con los repartos mercosureños. Por ejemplo, hay que apreciar si serán sectores privilegiados o populares, de ciertas regiones o de los países en su conjunto, etc. A semejanza de lo que se ha debatido en Europa, hay que determinar si se tratará o no de la integración "de los comerciantes". Es muy significativo considerar en qué aspectos de la vida se producen y producirán los beneficios y los perjuicios de la integración. Parecería que, pese a lo alegado, el Mercosur no cuenta a veces con móviles de compromiso de los gobernantes y la razonabilidad social generalizada deseables. Esto puede ser una de sus mayores debilidades.

17. Hay que atender a que los repartos pueden ser autoritarios, desenvueltos por imposición, y autónomos, desarrollados por acuerdo. Los primeros realizan el valor poder y los segundos satisfacen el valor cooperación. En el caso especial del monismo internacional e interno, los acuerdos entre los Estados plasmados en tratados se desenvuelven por autonomía, aunque en los marcos internos constituyan autoridad. Sin embargo, por ejemplo, la incorporación de Venezuela se produjo autónomamente pero sobre la base de la autoridad plasmada en la suspensión de Paraguay. Los alcances de la autonomía de los particulares en el ámbito del Derecho Privado del Mercosur ha motivado debates, pero se ha llegado a sostener que es muy amplia, sobre todo en el curso de la "lex mercatoria" ${ }^{\circ}$. El despliegue debido de la autonomía de los particulares puede fortalecer la integración.

18. El método ha de considerar que los repartos pueden presentarse ordenados, constituyendo un régimen que satisface el valor orden, o desordenados, en anarquía que realiza el "disvalor" arbitrariedad. El orden de repartos se produce según dos modos constitutivos, el plan de gobierno, con sentido vertical descendente, y la ejemplaridad, de modo horizontal. El plan de gobierno indica quiénes son los supremos repartidores (quiénes mandan) y cuáles son los criterios supremos de reparto (con qué criterios se manda). Se manifiesta por ejemplo en constitu-

60 Es posible c. GIMENEZ CORTE, Cristian, "Usos y Costumbre Jurídica y nueva lex mercatoria en América Latina con especial referencia al Mercosur" (tesis doctoral Facultad de Derecho de la Universidad Nacional de Rosario; aprobada con clasificación 10 -Sobresalientey recomendada para publicación; 8 de febrero de 2007), "Usos comerciales, costumbre jurídica y nueva "lex mercatoria" en América Latina. Con especial referencia al Mercosur", Bs. As., Ábaco, 2010. 
ciones, tratados en sus despliegues internos, directivas, leyes, decretos, sentencias, ordenanzas administrativas, etc. Cuando está en marcha realiza el valor previsibilidad. La ejemplaridad se desarrolla a través del seguimiento de repartos considerados razonables y se expresa en la costumbre, la lex mercatoria, la jurisprudencia, etc. Satisface el valor solidaridad. La anarquía puede ser institucional y teleológica, en la primera no se sabe quiénes mandan y en la segunda se ignora cuáles son los criterios con que se manda.

La planificación del Mercosur, expresada de modo principal en el Tratado de Asunción y sus protocolos, cuenta con una ejemplaridad muy diversificada según países, sectores y niveles de compromiso. Como de cierto modo ya se manifestó, el proyecto mercosureño no ha contado con el seguimiento debido de parte de varios gobiernos ${ }^{61}$ y poblaciones de frontera que han adoptado comportamientos claramente contrarios al sentido de la integración y han suscitado casos de anarquía, sobre todo teleológica (por ejemplo en cuanto al comercio y a las barreras o los obstáculos producidos por pobladores con cierto consentimiento gubernamental, v. gr. en los cortes de rutas). Los comportamientos internos a menudo no ordenados de las poblaciones de algunos países suelen provocar también debilidades para el proceso integrador ${ }^{62}$. Sin orden, la integración es muy difícil.

19. Los repartos y su orden pueden tropezar con límites necesarios surgidos de la denominada "naturaleza de las cosas". Pueden ser físicos, psíquicos, lógicos, sociopolíticos, socioeconómicos y de proyectos en cuestiones vitales. Los límites deben ser respetados o cambiados, no ignorados.

Los repartos y sus órdenes se producen en espacios constitucionales materiales, formados por los factores de poder. Si estos factores se oponen a lo pretendido es necesario hacerlos ceder para que lo pretendido sea posible.

El Mercosur viene tropezando con límites en la voluntad integra-

61 Suelen evidenciarse carencias para llegar a ser de manera suficiente un proyecto vital común.

Cabe considerar v. gr. RUBINO, María Angélica (Dra.), "Protocolo de medidas cautelares", en Seminario Internacional, "Derecho de la Integración", Los jueces ante el Mercosur, http:// www.salvador.edu.ar/dchointe.htm, 26-11-2012.

62 Vale tener presente por ej. NINO, Carlos Santiago, "Un país al margen de la ley", Bs. As., Emecé, 1992; Portal Guaraní, ROMERO SANABRIA, Aníbal, "La globalización y los diez pecados, capitales del paraguayo", http://www.portalguarani.com/obras_autores_detalles. php?id_obras=1722, 23-11-2012. Cabe c. asimismo los "Estudios Jurídicos del Bicentenario" cits., págs. 91 y ss. 
dora de ciertos gobernantes ${ }^{63}$; socioeconómicos, por obstáculos emergentes de los conflictos de intereses internos y externos, y de proyectos en cuestiones vitales, porque los dirigentes suelen creer que les es vital proyectarse al exterior abandonando las referencias integradoras y replantean e incluso abandonan las exigencias del proceso. Muchos factores de poder dejan las consideraciones mercosureñas procurando éxitos quizás sólo momentáneos. La estructura del Mercosur no tiene la solidez que deseamos y a veces los intereses de la confluencia son claudicantes. Tal vez la Unasur agregue un ingrediente de simpatía más amplia, pero sea todavía más difícil de estabilizar. En este despliegue de los límites necesarios se evidencian importantes debilidades de la integración.

20. Las categorías básicas de la dimensión sociológica del mundo jurídico más significativas en este caso son la causalidad, la finalidad subjetiva, la finalidad "objetiva" de los acontecimientos ${ }^{64}$, la posibilidad y la realidad. Todas, menos la finalidad subjetiva, se refieren al conjunto de de sus manifestaciones y en consecuencia nos son inabordables. Por eso tenemos que fraccionarlas produciendo certeza. El manejo de estas categorías tiene gran valor para la metodología jurídica. Por ejemplo, vale dominar la causalidad, la finalidad objetiva, la finalidad subjetiva, la posibilidad y la realidad ${ }^{65}$.

Cuando la finalidad subjetiva logra que la causalidad y la finalidad objetiva correspondan a ella los repartos son exitosos; si la finalidad objetiva corresponde a la finalidad subjetiva por otras causas, los repartos son "superados" y si la causalidad y la finalidad objetiva no llegan a corresponder a la finalidad subjetiva los repartos son fracasados. El manejo de las categorías brinda experiencia.

En el caso del Mercosur, la metodología categorial puede consistir por ejemplo en reducir, ampliar, sustituir o incluso suspender alcances del proceso integrador; en el establecimiento de acuerdos con otros países o procesos, etc. El manejo de las categorías puede ser relevante para la comprensión del carácter de proceso que tiene la integración.

63 V. por ej. Consejo Argentino para las Relaciones Internacionales, Argentina y Brasil 2015. Construyendo una visión compartida, Segunda Parte, Informe coordinado por Félix Peña y José Botafogo Gonçalves, http://www.cari.org.ar/pdf/argentina-brasil-2015-parte2.pdf, 26-122012. Asimismo puede v. El Atlántico, 08.08.2012, Brasil militarizó sus fronteras con Argentina Uruguay y Paraguay, http://www.diarioelatlantico.com/diario/2012/08/08/45100-brasil-militarizo-sus-fronteras-con-argentina-uruguay-y-paraguay.html, 26-11-2012). Según lo ya referido, quizás también la problemática de Botnia evidencie interés limitado en la integración.

$64 \mathrm{Al}$ menos las tenemos por objetivas.

65 Se puede ampliar en CIURO CALDANI, Miguel Angel, "Bases del pensamiento jurídico", Rosario, UNR Editora, 2012. 
Consideramos notorio que la integración sería más posible que su realidad actual si las finalidades subjetivas de sus gobernantes fueran más firmes en sostenerla y desarrollarla. Intereses y certezas que deberían ser momentáneos producen incluso debilidades y ciertos retrocesos en los niveles de integración. El tiempo transcurrido desde el origen del Mercosur permite juicios de éxito y frustración y brinda cierta experiencia.

\section{b) Dimensión normológica}

21. Entre los grandes interrogantes metodológicos del mundo jurídico está el del reconocimiento y la producción de las normatividades. En éstas se presentan en gran medida el dato histórico y sobre todo lo construido del planteo de la escuela de la libre investigación científica.

La propuesta del integrativismo tridimensionalista trialista, preocupada por la realización del Derecho en la vida de los seres humanos, construye la noción de norma como la captación lógica neutral de un reparto proyectado, respecto de la cual es particularmente importante el cumplimiento, productor de su exactitud ${ }^{66}$. Se requiere la metodología necesaria para que las normas sean exactas.

En este caso, importa que las normas mercosureñas obtengan exactitud, logro que a veces se realiza y en otros casos no. El Mercosur está lejos de ser un mercado común. Casos especialmente notorios de frecuente inexactitud son los obstáculos fronterizos para la circulación de personas y de mercaderías. Ante ciertos problemas, se plantea la debilidad de que intereses tácticos de circunstancias hacen dejar de lado la estrategia de la integración.

22. La norma es un juicio y como tal posee una estructura que consta de un antecedente, que capta el sector social a reglamentar, y una consecuencia jurídica, que capta su reglamentación. Cada uno posee características positivas, que deben estar presentes para que la norma funcione, y características negativas, que excluyen o concluyen su funcionamiento $^{67}$. La referencia a las distintas partes de la norma abre campos más comprensibles a movimientos metodológicos.

La estructura normativa de referencia se presenta también en las normas de la integración. Las partes de las normas son perspectivas

66 Un tema muy discutible, pero que merece importante consideración, es el expuesto por SANGUINETTI, Julio María, en "Un Mercosur sin leyes ni principios", La Nación, 25 de agosto de 2012, La Nación.com, http://www.lanacion.com.ar/1502304-un-mercosur-sin-leyes-ni-principios, 26-11-2012.

67 Se opta por una construcción compleja de la norma que pretende captar la plenitud compleja del reparto. 
para la comprensión lógica de la metodología normativa de la integración.

Incluso puede construirse al respecto una norma generalísima, sistematizadora de los problemas de la integración, inspirada en nuestro caso en la norma generalísima que sistematiza los problemas del Derecho Internacional Privado ${ }^{68}$. Como en todos los contactos de sistemas significativos diversos, las normas de integración generan el problema de las calificaciones, consistente en determinar qué Derecho determinará en última instancia los significados de los términos empleados. A menudo se utilizan calificaciones propias de las fuentes empleadas. Las características positivas del antecedente son el lugar de la delimitación de los problemas de integración. Las características negativas del antecedente brindan el sitio sistemático de las salvaguardas, que protegen la existencia diversa de los Estados y el rechazo del fraude a la ley, que resguarda a la estructura integrada del abuso de las partes. Las características positivas de la consecuencia jurídica constituyen el lugar de la configuración del espacio integrado, con sus distintas profundidades y las libertades fundamentales. Las características negativas de la consecuencia jurídica son el sitio de la reserva del orden público que resguarda al fin la individualidad de los Estados. El manejo de las posibilidades estructurales de los problemas es una fortaleza de la integración.

23. Las fuentes de las normas son reales o de conocimiento. Las primeras son materiales, los repartos mismos, o formales, las "autobiografías" de las normas elaboradas por los propios repartidores. Las fuentes de conocimiento constituyen la doctrina.

Las fuentes formales pueden ser más o menos flexibles o rígidas, según la facilidad o dificultad con que son elaboradas o modificadas; elásticas o inelásticas, conforme a su aptitud para adaptarse a los cambios de la realidad, y más o menos participativas, atendiendo a la intervención que los interesados tengan en elaboración. Es relevante, asimismo, la jerarquía material y formal que tengan en relación con otras normas. El empleo de diferentes fuentes corresponde a distintas soluciones metodológicas. Por ejemplo: una opción metodológica es la constitucionalización o el tratamiento constitucional de las cuestiones para brindar a sus soluciones los caracteres de rigidez y superioridad que poseen las fuentes constitucionales e internacionales.

Los procesos de integración suelen generar fuentes propias, incluso con denominaciones, flexibilidad o rigidez, elasticidad o inelasticidad y participación específicas. Las fuentes jurídicas del Mercosur son

68 Se presenta así la concepción normológica de la ciencia del Derecho de la Integración. 
sobre todo 1) el Tratado de Asunción, sus protocolos y los instrumentos adicionales o complementarios; 2) los acuerdos celebrados en el marco del Tratado de Asunción y sus protocolos; 3 ) las decisiones del Consejo del Mercado Común y las directivas de la Comisión de Comercio. A veces las fuentes producen cierta "inflación" legislativa. Un dato significativo es que las normas mercosureñas carecen de supranacionalidad. Aunque se ha afirmado la tendencia formal a reconocer supremacía a los tratados sobre las leyes, sucesos como los obstáculos en áreas fronterizas evidencian que la jerarquía de las fuentes en la materialidad es inferior a la que se indica en el nivel de las formas. Salvo la debilidad de la inexistencia de supranacionalidad, las fuentes formales mercosureñas son en general fortalezas que, sin embargo, no se concretan del mismo modo en la materialidad. Quizás se ha pretendido desde la forma más de lo que ésta puede brindar.

Existe ya un abundante material doctrinario que contribuye a consolidar el proceso integrador. La existencia de este material es una fortaleza mercosureña.

24. Para que los repartos proyectados captados en las normas lleguen a ser repartos realizados es necesario que éstas funcionen, cumpliendo en las medidas necesarias tareas de reconocimiento, interpretación, determinación, elaboración, aplicación y síntesis. El funcionamiento significa relaciones a menudo tensas entre los autores de las normas (v. gr. los legisladores) y los encargados de su funcionamiento (por ej. los jueces, administradores, etc.). Al fin cada uno hace lo que desea dentro de lo que puede, aunque ha de desear y querer lo valioso. Las normas y en correspondencia con ellas sus repartos proyectados, son lo que los encargados de su funcionamiento (v. gr. los jueces, administradores, etc.) las hacen ser dentro de lo que desean y pueden. Por esto es muy importante contar con encargados que estén suficientemente comprometidos con los proyectos de reparto, v. gr., a través de una jurisdicción especializada. Además del funcionamiento formal existe un funcionamiento conjetural, que influye en gran medida en el comportamiento de los interesados. El funcionamiento constituye un complejo metodológico de importancia.

El funcionamiento mercosureño ha de producirse, sobre todo en caso de necesidad de elaboración, atendiendo a que los Estados Parte tienen como objetivos principales el desarrollo económico con justicia social y la inserción internacional que incentive la competitividad externa de sus integrantes a través de la ampliación de sus mercados nacionales y la consolidación del poder en un bloque económico ${ }^{69}$.

69 En cuanto a los aspectos sociales se pueden v. por ej. Secretaría Permanente Mercosur 
El Mercosur se ha ocupado de ir avanzando en los métodos de solución de controversias y ha progresado especialmente con la constitución del Tribunal Permanente de Revisión, pero resultaría de gran significación contar con un órgano jurisdiccional del tipo de los Tribunales de las comunidades Europeas, que tanto hacen para la integración ${ }^{70}$. La ausencia de un tribunal de este tipo es una de las debilidades del proceso.

25. Al captar los repartos proyectados, las normas se valen de conceptos que les dan precisión e influyen en los sentidos que les atribuimos. Los conceptos integran los repartos proyectados. Pueden ser más institucionales o negociales, más o menos cargados de ideas y menos o más disponibles para los interesados. Desde este punto de vista se aprecia mejor lo que Gény denomina lo construido.

Aunque ha quedado dependiente de la intergubernamentalidad, el Mercosur ha dado a su institucionalidad el nivel máximo conceptual de persona jurídica y encomendó su ejercicio al Consejo del Mercado Común $^{71}$. Pese a que la intergubernamentalidad es una debilidad, la personalidad jurídica es una relativa fortaleza del proceso integrador.

26. Se considera que el ordenamiento normativo es la captación lógica neutral de un orden de repartos. El ordenamiento contiene el imperativo de la legalidad. Se constituye mediante relaciones verticales y horizontales, de producción y de contenido. Por las relaciones verticales de producción realiza el valor subordinación; por las vinculaciones verticales de contenido satisface el valor ilación; por las relaciones horizontales de producción realiza el valor infalibilidad y por las vinculaciones "horizontales" 72 de contenido satisface el valor concordancia. El conjunto realiza el valor coherencia. El ordenamiento contiene subordenamientos que se identifican al fin por el recurso a principios propios. Según las actitudes que asuman los encargados del funcionamiento ante las lagunas, los ordenamientos son meros órdenes, donde corresponde

Social, Declaración de Principios del Mercosur Social, Carta de Montevideo, http://www.mercosur-social.org/documentos/declaraciones/declaracion_de_principios_esp.pdf, 26-11-2012.

70 Tribunal Permanente de Revisión, http://www.tprmercosur.org/es/index.htm, 2511-2012; RUIZ DIAZ LABRANO, Roberto, "Las opiniones consultivas ante el Tribunal Permanente del Mercosur a través de los tribunales superiores de los Estados Partes", UNAM, http://www.juridicas.unam.mx/publica/librev/rev/dconstla/cont/2006.1/pr/pr29.pdf, 2511-2012. Se puede ampliar también en CIURO CALDANI, Miguel Angel, "Filosofía de la Jurisdicción - Con especial referencia a la posible constitución de un tribunal judicial del Mercosur", Rosario, Fundación para las Investigaciones Jurídicas, 1998, Cartapacio, http:// www.cartapacio.edu.ar/ojs/index.php/mundojuridico/article/viewFile/1092/996, 25-11-2012.

71 Art. 8, III del Protocolo de Ouro Preto sobre la Estructura Institucional del Mercosur.

72 Consideramos horizontales a las relaciones que no son verticales, por ejemplo, entre una resolución administrativa y una ley penal que la resguarda. 
consultar a los autores y éstos conservan el poder residual; sistemas materiales, donde los encargados del funcionamiento resuelven según lo consideren valioso (por autointegración o heterointegración) poseyendo ellos el poder residual, o sistemas formales, en los que los encargados deben resolver aplicando una regla de cierre (v. gr. la exigencia de ley previa para que haya delito y pena), de modo que el poder residual corresponde a los beneficiarios de estos cierres. Los meros órdenes suelen expresarse en recopilaciones y los sistemas en codificaciones.

Algunos facticidades opuestas a las normas manifiestan que el Mercosur posee un imperativo de legalidad no suficientemente fuerte. Como en todos los casos conviene establecer cuál es lugar en que se sitúan sus normas. Vale considerarlo como un subordenamiento con principios propios, distanciándolos si es necesario de los de la internacionalidad tradicional. Pese a la diversidad de sus fuentes, que sólo muestran una recopilación, conviene tratarlo como un subsistema material. La insuficiencia del sentido de legalidad es una debilidad del proceso integrador.

c) Dimensión dikelógica

27. Otro de los grandes interrogantes metodológicos del mundo jurídico se refiere a la construcción de la dimensión dikelógica. En ella se hace relativa referencia al dato racional del planteo de Gény.

Según la propuesta integrativista tridimensionalista trialista, el mundo jurídico ha de abarcar un complejo axiológico culminante en el valor justicia, que incluye además los valores utilidad, salud, verdad, belleza, amor, etc. El trialismo originario planteó un despliegue objetivo del valor justicia, pero un desarrollo trialista actual entiende que sobre puntos de partida adoptados, por ejemplo consentidos, es posible continuar el pensamiento dikelógico con rigor lógico sin caer en la posible no sustentabilidad de la objetividad ${ }^{73}$. La propuesta originaria del trialismo, hoy planteada como base construida, exige adjudicar a cada individuo la esfera de libertad necesaria para desarrollarse plenamente, es decir, para convertirse en persona.

Los valores pueden plantearse en relaciones de coadyuvancia o de oposición. Las primeras son siempre legítimas, las segundas pueden ser legítimas en la sustitución o ilegítimas en el secuestro del material estimativo de un valor por otro. El mundo actual es en gran medida escenario de tensiones entre los demás valores y la utilidad que, en lugar

73 Es posible ampliar en GOLDSCHMIDT, "La ciencia de la justicia (Dikelogía)" cit. CIURO CALDANI, "Metodología Dikelógica” cit. 
de coadyuvar o sustituirse. secuestra el material de los otros valores. En este marco el trialismo destaca la importancia del valor justicia.

Hoy las tensiones entre valores son producidas sobre todo por el despliegue capitalista, pero también se plantean en los procesos de integración donde, en marcos como el de la Unión Europea y el Mercosur, ha de procurarse de manera intensa que la utilidad no lleve a ignorar los requerimientos de justicia. De acuerdo con lo que plantea el trialismo, es necesario buscar que sin ignorar la Unión Europea y el Mercosur "de los comerciantes" se desarrollen la Unión y el Mercosur "de los pueblos". La fuerza de utilidad y sobre todo la vocación de justicia son fortalezas, pero ésta aún no ha logrado la concreción deseada.

28. Siguiendo enseñanzas de Aristóteles es posible reconocer caminos (métodos) para el pensamiento de la justicia, denominados clases de justicia. Entre estas clases se encuentran la justicia particular y la justicia general (orientada al bien común). La justicia particular es más afín al Derecho Privado y la justicia general se relaciona más con el Derecho Público. También es dado plantear la justicia "de partida" y la justicia "de llegada". La primera proyecta la situación existente, la segunda sacrifica lo existente en miras a llegar al objetivo pretendido. La justicia de llegada caracteriza más al progreso.

El despliegue de estas grandes opciones lleva a la necesidad de debatir si el Mercosur ha de tener más sentidos privatistas o publicistas, "de partida" o "de llegada". Parece que una de sus debilidades es la insuficiencia de sentidos de bien común y de llegada. No existe la debida aceptación de los sacrificios necesarios.

29. Como todo valor, la justicia vale, valora y orienta. Su sentido de valor es su valencia, su deber ser puro; la valoración es la referencia al material estimativo, que genera un deber ser ideal aplicado; la orientación se produce a través de criterios generales orientadores. El material estimativo de la justicia en el Derecho es la totalidad de las adjudicaciones pasadas, presentes y futuras ${ }^{74}$. Como este material es inabordable, porque no somos omniscientes ni omnipotentes, tenemos que fraccionarlo para ponerlo a nuestro alcance, produciendo seguridad jurídica.

Aunque se hacen frecuentes invocaciones de justicia, los procesos integradores como el Mercosur suelen requerir grandes reajustes ${ }^{75} \mathrm{en} \mathrm{su}$ material estimativo, generando cierta inseguridad. A menudo las partes no están dispuestas a aceptar las inseguridades respectivas, procurando

74 Por esto la justicia es pantónoma.

75 Incluso, por ejemplo, por armonizaciones. 
contar sólo con los beneficios, y esto es una de las debilidades del proceso.

A diferencia del Derecho, donde el material estimativo son principalmente las adjudicaciones, en la moral ese material son de manera predominante las virtudes y los vicios. El Derecho suele necesitar siempre apoyos morales; hay métodos de construcción moral del Derecho. También es relevante el despliegue moral del Mercosur. Lograrlo es una importante fortaleza a desarrollar ${ }^{76}$.

30. Una vez adoptado un principio supremo de justicia, como el que en este caso hemos propuesto (de adjudicar a cada individuo la esfera de libertad necesaria para desarrollarse plenamente) corresponde reconocer sus proyecciones en los repartos aislados y en el régimen. Construir la justicia "material" que esto significa es una de las mayores opciones metodológicas del Derecho.

La justicia de los repartidores como tales se logra principalmente a través de la autonomía construida con el acuerdo de todos los interesados; la paraautonomía del acuerdo de los interesados en que algunos repartidores se desempeñen como tales (v.gr. en el arbitraje); la infraautonomía por acuerdo de la mayoría (v. gr. en la democracia) y la criptoautonomía del acuerdo que brindarían los interesados en caso de conocer los repartos (como suele suceder en la gestión de negocios ajenos sin mandato). Otra referencia para la justicia de los repartidores es la aristocracia de la superioridad moral, científica o técnica. En el primer sentido, en el Mercosur se brindan espacios a la autonomía y la paraautonomía pero, pese al carácter democrático de los Estados, hay cierta carencia de participación democrática que puede constituir una significativa debilidad. La legitimación de los repartidores mercosureña se apoya también en la superioridad científica y técnica de repartidores calificados en estos asuntos. Cabe hacer referencia, por ejemplo, a los Comités Técnicos de la Comisión de Comercio.

La legitimidad de los repartidores trae consigo la problemática de su responsabilidad, por sus propios repartos y por el régimen. Parece que el Mercosur no ha logrado que sus gobernantes tengan pleno sentido de responsabilidad respecto del mismo y esto sería una de sus grandes debilidades.

La justicia respecto de los recipiendarios remite a los méritos pro-

76V.porej.PrincipioséticosmédicosdelMercosur,http://www.mercosur.int/msweb/Normas/ normas_web/Resoluciones/ES/Res_058_001_Princ-\%C3\%89ticos_M\%C3\%A9dicos_MCS_ Acta\%204_01.PDF, 26-11-2012. 
ducidos por la conducta y los merecimientos originados por las necesidades. El Mercosur tiene, por ejemplo, una Declaración Sociolaboral ${ }^{77}$ y una Declaración Social ${ }^{78}$. Sin embargo, pese a ciertos progresos, las grandes diferencias y marginalidades constituyen una de sus debilidades.

La legitimidad de los objetos se refiere principalmente a la vida y la propiedad. En cuanto a la vida, importa referirse a dar y quitar la vida, en este caso propia y ajena. Aunque los índices vitales han logrado avances, las condiciones de vida de los sectores marginales constituyen una de las debilidades del Mercosur ${ }^{79}$. Además del Mercosur del comercio y la propiedad debe existir un "Mercosur" como integración de la vida.

La justicia de la forma requiere audiencia de los interesados. Al respecto, la todavía deficiente participación democrática y la ausencia de un tribunal ordinario relativamente análogo al de las Comunidades Europeas constituyen debilidades del Mercosur.

La legitimidad de las razones exige fundamentación. Con la fundamentación se completa la bilateralidad de la comunicación abierta por la forma. Parece que el Mercosur no ha logrado fundamentarse en parte de la población y esto puede constituir una de sus debilidades.

31. Un régimen resulta justo cuando considera a cada individuo como un fin y no como un medio. Esto significa que es humanista y no totalitario. El humanismo requiere considerar a cada hombre único, igual y parte de una comunidad. Una de las fortalezas del Mercosur son sus sentidos humanista y a menudo igualitario, pero es necesario afirmar la referencia a la comunidad mercosureña.

Para realizar el régimen de justicia hay que amparar al individuo contra todas las amenazas: de los demás individuos, el régimen, sí mismo y todo "lo demás" (enfermedad, miseria, ignorancia, soledad, desempleo, etc.). La protección contra el régimen exige el debilitamiento de éste a través de la división del poder en la materia, el espacio, el tiempo

77 V. Declaración Sociolaboral del Mercosur, http://www.sice.oas.org/labor/MERCOSUR_ Sociolab.pdf, 26-11-2012.

78 Ya citada.

79 V. PNUD, Informe sobre desarrollo humano para Mercosur 2009-2010, http://books. google.com.ar/books?id=egCWb4QtQ9IC\&pg=PA302\&lpg=PA302\&dq=mortalidad + in fantil+mercosur\&source $=$ bl\&ots $=$ x $2 \mathrm{gNpZ2}$ ntu \&sig $=\mathrm{gQfa} 8 \mathrm{ntHos} U \mathrm{dzd}$ APs0TQQLE0JR $s \& h l=e s-419 \& s a=X \& e i=l u q z U I q q C I W A 9 g T q-o G I C w \& v e d=0 C D Q Q 6 A E w A j g K \# v=$ one page \&q=mortalidad\%20infantil\%20mercosur\&f=false , 26-11-2012; ROJAS CABRERA, Eleonora Soledad y otras, "La mortalidad infantil en el Mercosur desde una perspectiva de derechos humanos", http://www.alapop.org/2009/SerieInvestigaciones/Serie10/ Serie10.2RojasSantillan.pdf, 26-11-2012. 
y las personas y el fortalecimiento de los individuos mediante los derechos humanos y sus garantías. Es necesario asimismo el resguardo de las minorías. La formación del complejo de este resguardo ${ }^{80}$ es uno de los ámbitos metodológicos de gran significación.

Además de lo que hacen dentro de ellos los Estados Parte, el Mercosur viene organizando medios para proteger a los individuos contra los demás, por ejemplo en cuestiones procesales ${ }^{81} \mathrm{y}$ penales; respecto de los regímenes, mediante el compromiso con la democracia ${ }^{82}$ y los derechos humanos ${ }^{83}$ y frente a lo demás, v. gr. en la ya referida política social. Esta protección es en general una fortaleza del Mercosur.

\section{2) El mundo jurídico en sus especialidades de materia, espa- cio, tiempo y personas}

32. Los despligues comunes al mundo jurídico se diversifican tridimensionalmente en la materia, el espacio, el tiempo y las personas. Las diversidades en la materia constituyen de modo principal ramas jurídicas. Algunas son tradicionales como el Derecho Constitucional, el Derecho Administrativo, el Derecho Penal, el Derecho Procesal, el Derecho Civil, el Derecho Comercial, el Derecho del Trabajo y el Derecho Internacional, Público y Privado. Otras son más evidentes en la actualidad, como el Derecho de la Salud y el Bioderecho, el Derecho de la Ciencia, el Derecho del Arte, el Derecho de la Educación, el Derecho

80 A menudo hay que proteger también contra la "protección".

81 VÉSCOVI, Enrique, "Derecho Procesal Internacional. Uruguay, el Mercosur y América", Montevideo, Idea, 2000; AS. VS., "El Derecho Procesal en el Mercosur - Libro de Ponencias", Facultad de Ciencias Jurídicas y Sociales de la Universidad Nacional del Litoral, 1997; FEUILLADE, M. C., "Cooperación jurisdiccional civil de primer grado : tratamiento de los exhortos o cartas rogatorias", en "Prudentia Iuris", 68-69, págs. 185-246, Biblioteca Digital de la Universidad Católica Argentina, http://bibliotecadigital.uca.edu.ar/repositorio/revistas/cooperacion-jurisdiccional-civil-primer-grado.pdf , 26-11-2012; RUIBAL PINO, Jorge, "Cooperación penal en el ámbito del Mercosur", http://www.fam.org.ar/media/downloads/ institutos/PonenciaDrRuibal\%20cooperacion\%20penal\%20en\%20MERCOSUR.pdf , 16-112012; ALVAREZ, Alejandro E., "La internacionalización del Derecho Penal: el ejemplo del Mercosur", en "Anuario de Derecho Constitucional Latinoamericano", 2003, págs. 485 y ss., UNAM, http://www.juridicas.unam.mx/publica/librev/rev/dconstla/cont/2003/pr/pr27.pdf , 26-11-2012.

82 Entre sus bases cabe mencionar, por ej., el Protocolo de Ushuaia sobre compromiso democrático en el Mercosur, la Republica de Bolivia y la Republica de Chile, http:// www.mercosur.int/msweb/Normas/Tratado $\% 20 \mathrm{e} \% 20$ Protocolos/1998_ProtocoloUshuaiaCompromisoDemocr\%C3\%A1tico_ES.pdf, 1-12-2012.

83 V. por ej. Observatorio de Políticas Públicas en el Mercosur, v. gr., Protocolo de Asunción sobre Compromiso con la Promoción y Protección de los Derechos Humanos del Mercosur, http://www.observatoriomercosur.org.uy/es/obsd23.php, 1-12-2012; LUCAS GARIN, Andrea, "Derechos humanos en clave de Mercosur", en "Revista Brasileira de Direito Constitucional - RBDC”, n. 15 - jan./jun. 2010, http://www.esdc.com.br/RBDC/RBDC-15/RBDC-15027-Andrea_Lucas_Garin_\%28Derechos_Humanos_en_clave_de_MERCOSUR\%29.pdf, 2-12-2012. 
Ambiental, el Derecho de Menores, el Derecho de la Ancianidad, etc. Todas las especificidades son perspectivas legítimas de consideración en el Mercosur ${ }^{84}$. Viene trabajándose en varios de estos campos y mucho cabe hacer para un desarrollo integral.

\section{Conclusión}

33. El integrativismo tridimensionalista trialista brinda recursos metodológicos socio-normo-dikelógicos de importancia para comprender y resolver de maneras más valiosas las cuestiones estratégicas del Mercosur.

84 En el horizonte del mundo jurídico se construye el integrativismo tridimensionalista del mundo político, constituido por actos de coexistencia captados por normas y valorados por el conjunto de los valores de convivencia. En este mundo hay diversas ramas signadas por referencias a valores de convivencia o a consideraciones de conjunto: por ejemplo, además de la política jurídica (valor justicia, mundo jurídico), la política sanitaria (salud), la política económica (utilidad), la política científica (verdad), la política artística (belleza), la política erótica (amor), la política educacional (expansión del complejo), la política de seguridad (limitación del complejo), etc. Este horizonte se presenta también en la consideración jurídica del Mercosur y puede enriquecer su metodología. 